\title{
Market Values of Fiber Properties in Southeastern Textile Mills ${ }^{4}$
}

\author{
Joel F. Hembree, Don E. EThridge, and Jarral T. NeEper \\ Natural Fibers and Food Protein Commission of Texas and Department of Agricultural Economics, \\ Texas Tech University, Lubbock, Texas 79409, U.S.A.
}

\begin{abstract}
Effects of fiber properties (length, length uniformity, strength, micronaire, white, yellow, and trash content) on U.S. mill prices of cotton were estimated. USDA data on fiber properties and mill prices on cottons from four production regions in the U.S. were used in the statistical analysis. All fiber properties were found to significantly affect mill prices; the fiber properties having the greatest influence were fiber strength, length, and micronaire, followed by length uniformity, yellowness, whiteness, and trash content. These properties explained $18 \%$ of the total variation in mill prices between 1977/78 and 1983/84.
\end{abstract}

The systems for grading, marketing, and processing cotton fiber are complex in comparison to most raw or semiprocessed commodities. For example, textile processing transforms fiber into a broad range of products that are quite diverse in their characteristics. Furthermore, these transformations are accomplished in plants with different kinds of technology (e.g., rotor and ring spinning), equipment, and fiber mixes. In the marketing system, ownership of cotton may change several times before delivery to a textile mill. The cost and complexity in marketing are increased by the maintenance of the individual identity and information about each unit (bale) of cotton throughout the system. The inherent heterogeneity of the cotton fiber results in a quality evaluation system with several important dimensions and several thousand combinations of attributes with which the marketing and processing sectors must deal.

New technology in the form of high volume instrument (HVI) quality determinations on cotton by the USDA presents the industry with another adjustment transition. An HVI generates information on more fiber properties and generates more reliable (repeatable) information on properties than are included in the traditional classification system. The producing, marketing, and processing segments of the cotton industry are in the process of understanding the new data and how to use it. Through the interaction of buyers and sellers of cotton throughout the marketing channel, prices are being generated for different cottons, but because there are so many prices on such diverse kinds of cotton, the price signals being generated by the markets are not clear, i.e., there is no clear understanding of what fiber characteristics the market in general is paying for.

\footnotetext{
'Presented at the Cotton Textile Conference, Beltwide Cotton Research Conference, New Orleans, Louisiana, January 1985.
}

The objective of our study was to estimate the market values of fiber properties in the southeastern U.S. textile mill market. Our purpose was to provide a more reliable and thorough understanding of the value of specific fiber properties in that market. The information is relevant to textile mill management, merchants, breeders, and cotton producers. Furthermore, the increased understanding by all parties should increase the pricing and operational efficiencies of the production and marketing systems.

Numerous studies of the relationship between cotton prices and fiber properties have been conducted in the past 20 years. Hembree and Sattar developed a quality index for fiber properties of world cottons in 1954 using Liverpool prices [16]. Several studies between 1915 and 1940 analyzed relationships between grade and staple and prices received by farmers $[1,9,10,11,14,17]$. All of those early studies used single-variate statistical techniques and several concluded that farm prices did not accurately reflect use value of cotton. In more recent years (since 1965), Newton et al. [13] reached the same conclusion. A study of farm prices in Louisiana examined fiber properties other than grade, staple, and micronaire, but found little influence from them [12]. A study of HVI impacts in Texas had similar findings for producer prices $[4,15]$. Another study of markets in Texas found some significant correlations between fiber properties and prices [8], but the absence of a model limited the implications of the analysis.

\section{Methods and Procedures}

The method of analysis we used in this study evolved from an approach known as hedonic price estimation $[2,7]$. The conceptual basis of hedonic prices is that goods have value only through the useful characteristics 
embodied in them. Previous hedonic price analysis on cotton provided a partial estimation model framework for this study $[2,3,4,5,15]$. The model used in this study was

$$
P=f(L, U, M, S, W, Y L, T R, Y R)
$$

where $P=$ landed mill price of cotton in February at southeastern U.S. group 201 mill points, $\$ / l b ; L=$ fiber length of cotton delivered to southeastern mills, inches; $U=$ uniformity index of the cotton, digital Fibrograph $50 / 2.5$ uniformity ratio; $M=$ micronaire reading of the cotton; $S=$ fiber strength of the cotton, grams/tex; $W=$ whiteness of the cotton, $R_{d}$ (the larger the index, the whiter the fiber); $Y L=$ yellowness of the cotton, $+b$ (the larger the index, the more yellow); $T R=$ trash content of the cotton, first digit of the grade code; and $Y R=$ year of the purchase, measured with binary indicator variables with 1983 the base year.

USDA Agricultural Marketing Service data on prices and fiber tests were used with the model. The data on fiber properties were obtained from the annual Summaries of Cotton Fiber and Processing Test Results [19]. All average test results for short, medium and extra long staple groups for the Southeast, South Central, High Plains, Rio Grande Valley, and West for each of seven years, 1977/78 through 1983/84, were used (Table 3 in each annual publication). This provided the major grade/staple groups from each region in each year and the corresponding average fiber properties of each group. The fiber properties in the data set were region averages, so part of the variation in properties within regions has been eliminated. The corresponding landed mill price for each observed group was obtained from weekly average f.o.b. mill prices at group 201 mill points [18] for five growth areas: southeastern growths (for southeastern region cotton), Memphis territory growths (for the south central region), California growths (for the west), TexasOklahoma growths (for southwest short and medium staple cotton), and El Paso growths (for western extra long staple cotton). Quoted prices for selected combinations of grades and staples for which there were corresponding instrument data from crop spinning tests were used. Early-to-mid February price quotations were used for each crop year because February prices tend to closely approximate annual average prices. Thus, price quotations used were for February 9, 1978; February 9, 1979; February 14, 1980; February 12, 1981; February 11, 1982; February 17, 1983; and February 16,1984 . A total of 155 observations over the seven years was used, but the observations were not evenly distributed across regions or time. Of the 155 observations, 42 were for southwest short staple, 23 south- east, 33 south central, 21 southwest medium staple, and 36 west. Observations by year were $24,28,31,29$, 19,17 , and 7 for $1977 / 78$ through $1983 / 84$, respectively.

Several adjustments were made in the fiber properties data because of changes in values reported over the seven-year period. The 1977-1979 quality data on whiteness and yellowness were reported as a code number and both converted to $R_{d}$ and $+b$ using adjustment factors reported by the USDA [19]. Prior to 1982, data on fiber length and length uniformity were reported as $2.5 \%$ span length and 50/2.5 uniformity, respectively; beginning in 1982, these were reported as HVI upper half mean and mean/upper half mean (M/ UHM) uniformity, respectively. Measurements for 1982 and 1983 were adjusted to conform to earlier period measurements using equivalency conversions reported by the USDA [19].

The multiple linear regression model specified was linear in all variables except micronaire, which was included as a quadratic form. This conformed to previous analytical studies using similarly limited data sets $[2,4,15]$. The dummy variables for years were as follows: $D 1=1$ if year was 1977,0 otherwise; $D 2=1$ if year was 1978,0 otherwise; $D 3=1$ if year was 1979 , 0 otherwise; $D 4=1$ if year was 1980,0 otherwise; $D 5$ $=1$ if year was 1981,0 otherwise; and $D 6=1$ if year was 1982,0 otherwise. Thus, the regression model was

$$
\begin{aligned}
P & =B_{0}+B_{1} L+B_{2} U+B_{3} M+B_{4} M^{2}+B_{5} S \\
& +B_{6} W+B_{7} Y L+B_{8} T R+B_{9} D 1+B_{10} D 2 \\
& +B_{11} D 3+B_{12} D 4+B_{13} D 5+B_{14} D 6+e,
\end{aligned}
$$

where $B_{i}=$ parameters, $i=0, \ldots, 15$, and $e=$ stochastic error term.

The estimated $B_{i}$ values indicate the relationship between each of the independent variables and the mill price of cotton. Standardized regression coefficients (which indicate the relative impact independent of units of measurement) of each independent variable on price were also determined. In addition, the effect of each independent variable on price was estimated after adjusting for the indirect effects of other independent variables (see Ferber [6]). Each independent variable has a direct effect on the mill price, but each variable may also have an indirect effect on mill price through its relationship with other independent variables. The direct effect of an independent variable is computed as the standardized regression coefficient squared; the indirect effect of an independent variable is computed as

$$
\sum_{j} b_{i} b_{j} r_{i j}, i \neq j
$$


where $b_{i}=$ standardized regression coefficient for the independent variable for which the indirect effect is being estimated, $b_{j}=$ standardized coefficient for another independent variable, and $r_{i j}=$ coefficient of simple correlation between the two independent variables.

The total effect, the contribution of the independent variable to the coefficient of multiple determination $\left(R^{2}\right)$, is the sum of the direct effect of the variable (always positive) and the various indirect effects (each may be positive or negative).

\section{Findings}

Results from the ordinary least squares estimation are summarized in Table 1 . All of the indicator variables were highly significant, indicating that the general price level for cotton in each of the seven years was different from that in $1983 / 84$. The parameter estimates show that, e.g., mill prices were about $17 \$ / \mathrm{lb}$ lower in $1977 /$ 78 and $12 \$ / \mathrm{lb}$ higher in $1980 / 81$ than in $1983 / 84$, after adjusting for the effect of quality variation between years. The significance of the indicator variables for purposes of this analysis, however, was to control for the effects of market forces on the general price level so that values of fiber properties could be estimated independent of the general market forces.

TABLE l. Estimated effects of variables on southeastern U.S. textile mill prices, 1977/78-1983/84.

\begin{tabular}{|c|c|c|c|}
\hline Variable & $\begin{array}{l}\text { Estimated } \\
\text { regression } \\
\text { coefficient }\end{array}$ & 1-value & $\begin{array}{l}\text { Standardized } \\
\text { regrcssion } \\
\text { coefficient }\end{array}$ \\
\hline lntercept & -44.09 & $-1.95^{\mathrm{a}}$ & 0.000 \\
\hline L & 20.98 & $2.79^{\mathrm{b}}$ & 0.093 \\
\hline $\mathrm{U}$ & -0.91 & $-3.92^{\mathrm{r}}$ & -0.077 \\
\hline$M$ & 46.87 & $8.73^{c}$ & 1.662 \\
\hline $\mathrm{M}^{2}$ & -4.87 & $-7.55^{c}$ & -1.400 \\
\hline $\mathrm{S}$ & 1.45 & $6.07^{\mathrm{c}}$ & 0.172 \\
\hline W & 0.32 & $2.44^{\mathrm{s}}$ & 0.066 \\
\hline YL & -2.52 & $-4.52^{\mathrm{C}}$ & -0.125 \\
\hline TR & -2.29 & $-3.83^{b}$ & -0.092 \\
\hline D1 & -17.24 & $-13.59^{\mathrm{r}}$ & -0.472 \\
\hline D2 & -9.14 & $-7.84^{\mathrm{c}}$ & -0.266 \\
\hline D3 & 13.56 & $11.24^{\mathrm{F}}$ & 0.411 \\
\hline D4 & 11.99 & $\left.11.3\right|^{\mathrm{c}}$ & 0.354 \\
\hline D5 & -13.22 & $-11.75^{\mathrm{e}}$ & -0.328 \\
\hline D6 & -8.77 & $-7.45^{\mathrm{c}}$ & -0.207 \\
\hline
\end{tabular}

The results indicate that during the $1977 / 78-1983 /$ 84 period, all fiber properties included in the model had a significant impact on mill prices. Over the range of quality attributes included in the sample, an increase of one gram/tex in fiber strength, other fiber properties constant, increased the average price paid by southeastern textile mills by $1.45 \$ / \mathrm{lb}$. An increase in trash content by one digit of the grade code decreased mill prices paid by $2.29 \Phi / \mathrm{lb}$. All signs of the coefficients were as expected except for the negative sign on the uniformity index; as the uniformity index increased by one unit, the mill price decreased by $.91 \mathrm{\$} / \mathrm{lb}$. This relationship is strong and statistically significant, but it is not consistent with what textile mills specify as desirable. We have not found a satisfactory explanation and no cause-effect conclusion should be drawn, but it may be noted that length uniformity is the only fiber property not widely recognized in the marketing system in some manner, i.e., through reported prices, contract specifications, etc.

The overall model explained $96.9 \%$ of the variation in mill prices across regions of origin of the cotton during the study period $\left(R^{2}=0.969\right)$, and the model was statistically significant at the 0.0001 level. Analysis of residuals revealed no problems with nonrandom error terms, so all statistical tests were deemed valid. The single concern regarding the reliability of the model was with the high correlation of fiber length with strength and yellowness; simple correlation coefficients were 0.73 and -0.71 , respectively. These correlations indicate association, not causal relationships, and they are probably genetically determined. They do, however, limit the information obtained from the standardized regression coefficients. The standardized coefficients suggest that the rank order of fiber properties in explaining mill prices is micronaire, strength, yellowness, length, trash, length uniformity, and whiteness, but the direct and indirect effects as determined by the procedure explained above reveal a different ranking (Table II).

TABLE II. Contributions of variables to southeastern U.S. textile mill prices for cotton, 1977/78-1983/84.

\begin{tabular}{llll}
\hline \multicolumn{1}{c}{ Variable } & $\begin{array}{l}\text { Direct } \\
\text { effect }\end{array}$ & $\begin{array}{c}\text { Indirect } \\
\text { effect }\end{array}$ & $\begin{array}{r}\text { Total } \\
\text { effect }\end{array}$ \\
\hline $\begin{array}{l}\text { Length } \\
\text { Length }\end{array}$ & .0086 & .0201 & .0287 \\
$\begin{array}{l}\text { uniformity } \\
\text { Micronaire }\end{array}$ & .0058 & .0153 & .0211 \\
Strength & .0677 & -.0393 & .0284 \\
Whiteness & .0293 & .0240 & .0533 \\
Yellowness & .0044 & .0113 & .0157 \\
Trash & .0156 & .0032 & .0188 \\
D1 & .0083 & .0039 & .0122 \\
D2 & .2207 & .0114 & .2321 \\
D3 & .0702 & .0003 & .0705 \\
D4 & .1670 & -.0017 & .1653 \\
D5 & .1242 & .1114 & .2356 \\
D6 & .1066 & -.0199 & .0867 \\
Total & .0004 & -.0003 & .0001 \\
& & & .9685 \\
\hline
\end{tabular}


Table II shows that fiber strength had the greatest impact among fiber properties on mill prices paid during the study period, followed by length and micronaire, length uniformity, yellowness, whiteness, and trash content. Among the fiber properties, the variables evaluated fall into distinct categories ranked by their mill values: (a) strength, (b) length and micronaire, (c) length uniformity and yellowness, and (d) whiteness and trash.

While the model explained $96.9 \%$ of the variation in textile mill prices, the fiber properties explained only $17.8 \%$. The remaining $79.1 \%$ of price variation was explained by general market forces, which varied among years (indicated by $D 1$ through $D 6$ in the model). This indicates that overall market supply and demand forces have a larger impact on prices paid for cotton by textile mills than do fiber properties, but fiber properties are nevertheless a significant and substantial part of prices paid.

\section{Conclusions}

The results of this study demonstrate that fiber properties have a significant impact on prices paid for cotton by U.S. textile mills. The effect of fiber properties on mill prices is small compared to the effects of general market forces, but the extent to which fiber properties influence prices is larger than may be commonly believed. Among the fiber properties, fiber strength had the greatest effect on mill prices paid during the study period, followed by fiber length and micronaire, fiber length uniformity and yellowness, and fiber whiteness and trash content. We anticipaled the importance of length and micronaire, but the relative importance of fiber strength may be an unanticipated result to many in the industry. The relative importance of fiber properties such as strength suggests that these properties may need to be included in the official reporting of market prices.

While fiber properties explained $17.8 \%$ of the total variation in the average prices for the 7-year period, they explain a greater proportion of price variation within any year. If market conditions were stable (no variation in $D 1-D 6$ ), then the fiber properties explain $85 \%$ of the variation in average mill prices across regions $(17.8 \%$ of the portion not explained by $D 1-D 6$, or $20.1 \%$ ).

Several conditions of the study should be remembered when applying the results. The explanatory power of the estimates in the model is derived in substantial part from the cross-region nature of the data. The differences in fiber properties and prices paid among regions provide the model with a capability to differentiate the values of fiber properties. In addition, the av- erage fiber properties and average prices for the regions affect the explanatory power of the model. Less total variation in mill prices might have been explained with a more disaggregated data set.

The results apply for the $1977 / 78-1983 / 84$ period and the values of specific fiber properties may, and probably will, change in the future. The prices paid for fiber properties by textile mills are affected by the demand for a specific fabric and the contribution of each property in spinning, weaving, and other manufacturing processes. The use value is thus affected by factors such as the kind of end products being produced by textile mills and the spinning technology (ring spinning, rotor spinning, etc.), and these factors change over time. The prices paid for fiber properties are also affected by the supply of those fiber properties, and the production of fiber properties may also change over time. This also causes market values of fiber properties to not be static within an area or between areas. As market signals provide information with respect to the value of fiber strength, for example, producers will call on geneticists to increase the fiber strength characteristics of cotton, and more fiber strength may be produced. If the demand for fiber strength stays constant and the supply of strength increases, the market value of fiber strength will decline.

\section{ACKNOWLEDGMENTS}

The research was supported by the Agricultural Marketing Service, U.S. Department of Agriculture; The Natural Fibers and Food Protein Commission of Texas; the Texas Agricultural Experiment Station; and the Institute for Food and Fiber Production in Arid and Semi-Arid Lands, Texas Tech University. We acknowledge the contributions of Bob Davis, Dean Hughes, and Harvin Smith for suggestions on the manuscript and of Geane Hall and P. S. Roy for assistance on statistical evaluations. Texas Tech University College of Agricultural Sciences publication no. T-1-221.

\section{Literature Cited}

1. Crawford, G. L., and Gabbard, L. P., Relation of Farm Prices to Quality of Cotton, Tex. Agr. Exp. Sta. Bulletin No. 383, July 1928.

2. Ethridge, Don E., and Davis, Bob, Hedonic Price Estimation for Commodities; An application to Cotton, West. J. Agr. Econ. 7 (2), 293-300 (1982).

3. Ethridge, Don E., and Mathews, Kenneth H., Reliability of Spot Cotton Quotations for Price Discovery in the West Texas Cotton Market, Ag. Econ. Dept., Texas Tech Univ. College of Ag. Sci. pub. no. T-1-212, Aug. 1983.

4. Ethridge, Don E., Shaw, Dale L., and Ross, John E., An Evaluation of Impacts of Instrument Test Line Values on Cotton Marketing and Use: Progress Report, CED 
Working Paper, Econ. Res. Serv., USDA, Texas Tech Univ. Coll. of Ag. Sci. pub. no. T-1-157, Aug. 1977.

5. Ethridge, Don E., Sudderth, Randy, and Moore, Mark, A Model for Cotton Variety Selection with Yield and Quality Considerations, in "Proc. 1983 Cotton Research Conferences," Cotton Economics and Marketing Conference, Natl. Cotton Council, San Antonio, Jan. 3-4, 1983.

6. Ferber, Robert, "Statistical Techniques in Market Research," McGraw-Hill, New York 1949, pp. 361-367.

7. Griliches, Zvi, Ed., "Price Indexes and Quality Change," Harvard University Press, Cambridge, Mass., 1971.

8. Horak, John D., Cotton Pricing According to Fiber Properties, Natural Fibers Economic Research, The Univ. of Texas at Austin, research rep. no. 110, Dec. 1976.

9. Howelt, L. D., and Burgess, John S., Farm Prices of Cotton as Related to its Grade and Staple Length in the United States, Seasons 1928-29 to 1932-33, USDA tech. bul. no. 493, Jan. 1936.

10. Howell, L. D., and Hembree, Joel F., Farm Prices of Cotton Related to Grade and Staple Length in the United States, mimeographed report, Cotton Division, USDA, 1935.

11. Howell, L. D., and Watson, Leonard J., Cotton Prices in Relation to Cotton Classification Service and to Quality Improvement, USDA tech. bul. no. 699, Oct. 1939.

12. Hudson, James F., and Williams, Douglas R., Relation- ship of Fiber Test Data and Other Factors to Prices Paid for Louisiana Cotton, Louisiana State Univ. D.A.E. research report no. 482, Apr. 1975.

13. Newton, Franklin E., Burley, Samuel T., Jr., and LaFerney, Preston E., Does Cotton Price Reflect Use Value? Textile Manag. Eng. J. 131 (7), 76-80 (1967).

14. Paulson, W. E., and Hembree, Joel F., Price-Quality Relationships in Farmers' Cotton Markets of Texas, Tex. Agr. Exp. Sta. bul. no. 501, Dec. 1934.

15. Robinson, Jess A., Ethridge, Don E., Shaw, Dale L., and Rodgers, Clarence D., Market Impact Evaluation of the Instrument Testing of Cotton: 1977 Crop Progress Report, CED Working Paper, Econ., Stat., \& Coop. Serv., USDA, Texas Tech Univ. Coll. of Agr. Sci. pub. no. T-1-184, May 1979.

16. Sattar, Abdus, Fiber Properties and Production of World Cottons and Their Use in Merchandising Cotton, Cotton Economic Research, The University of Texas, research project no. 49, 1954.

17. Taylor, Fred, Relation Between Primary Market Prices and Qualities of Cotton, USDA bul. no. 457, Nov. 24, 1916.

18. USDA, Cotton Market News; Southern and Western Review, Agricultural Marketing Service, 2/9/78, 2/9/79, $2 / 14 / 80,2 / 12 / 81,2 / 11 / 82,2 / 17 / 83,2 / 16 / 84$.

19. USDA, Summary of Cotton Fiber and Processing Test Results, Agricultural Marketing Service, Cotton Division, annual issues 1977-1983. 